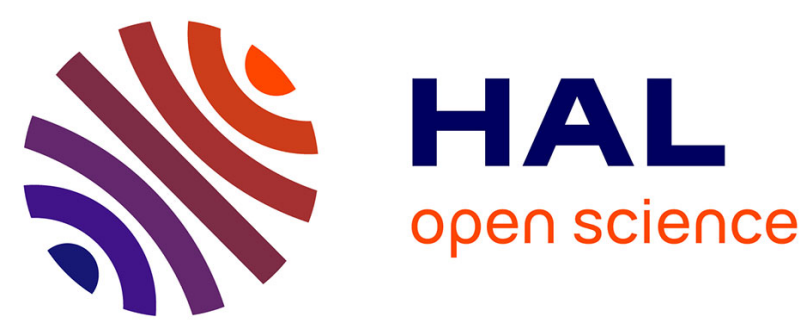

\title{
Changes in metal nanoparticle shape and size induced by swift heavy-ion irradiation
}

M. Ridgway, P. Kluth, R. Giulian, D. Sprouster, L. Araujo, C. Schnohr, D. Llewellyn, A. Byrne, G. Foran, D. Cookson

\section{- To cite this version:}

M. Ridgway, P. Kluth, R. Giulian, D. Sprouster, L. Araujo, et al.. Changes in metal nanoparticle shape and size induced by swift heavy-ion irradiation. The Seventh International Symposium on Swift Heavy Ions in Matter, Jun 2008, Lyon, France. hal-00256222

\section{HAL Id: hal-00256222 \\ https://hal.science/hal-00256222}

Submitted on 14 Aug 2008

HAL is a multi-disciplinary open access archive for the deposit and dissemination of scientific research documents, whether they are published or not. The documents may come from teaching and research institutions in France or abroad, or from public or private research centers.
L'archive ouverte pluridisciplinaire HAL, est destinée au dépôt et à la diffusion de documents scientifiques de niveau recherche, publiés ou non, émanant des établissements d'enseignement et de recherche français ou étrangers, des laboratoires publics ou privés. 


\title{
Changes in metal nanoparticle shape and size induced by swift heavy-ion irradiation
}

\author{
M.C. Ridgway ${ }^{1}$, P. Kluth, R. Giulian, D.J. Sprouster, L.L. Araujo, C.S. Schnohr \\ and D.J. Llewellyn \\ Department of Electronic Materials Engineering, \\ Research School of Physical Sciences and Engineering, \\ Australian National University, Canberra, Australia \\ A.P. Byrne ${ }^{2}$ \\ Department of Physics, Faculty of Science, \\ Australian National University, Canberra, Australia \\ G.J. Foran \\ Australian Nuclear Science and Technology Organisation, Menai, Australia \\ D.J. Cookson \\ Australian Synchrotron, Melbourne, Australia
}

Changes in the shape and size of Co, Pt and Au nanoparticles induced by swift heavy-ion irradiation (SHII) have been characterized using a combination of transmission electron microscopy, small-angle x-ray scattering and x-ray absorption near-edge structure. Elemental nanoparticles of diameters 2-15 nm were first formed in amorphous $\mathrm{SiO}_{2}$ by ion implantation and thermal annealing and then irradiated at room temperature with $27-185$ $\mathrm{MeV} \mathrm{Au} \mathrm{ions} \mathrm{as} \mathrm{a} \mathrm{function} \mathrm{of} \mathrm{fluence.} \mathrm{Spherical} \mathrm{nanoparticles} \mathrm{below} \mathrm{a} \mathrm{minimum} \mathrm{diameter}$ (4-7 $\mathrm{nm})$ remained spherical under SHII but progressively decreased in size as a result of dissolution into the $\mathrm{SiO}_{2}$ matrix. Spherical nanoparticles above the minimum diameter threshold were transformed to elongated rods aligned with the ion beam direction. The nanorod width saturated at an electronic-energy-deposition dependent value, progressively increasing from 4-6 to 7-10 $\mathrm{nm}$ (at 5 to $18 \mathrm{keV} / \mathrm{nm}$, respectively) while the nanorod length exhibited a broad distribution consistent with that of the unirradiated spherical nanoparticles. The threshold diameter for spherical nanoparticle elongation was comparable to the saturation value of nanorod width. We correlate this saturation value with the diameter of the 
molten track induced in amorphous $\mathrm{SiO}_{2}$ by SHII. In summary, changes in nanoparticle shape and size are governed to a large extent by the ion irradiation parameters.

${ }^{1}$ corresponding author: mark.ridgway@ anu.edu.au

${ }^{2}$ also: Department of Nuclear Physics, Research School of Physical Sciences and Engineering, Australian National University, Canberra, Australia.

PACS codes: 61.80.Jh, 61.82.Rx, 61.10.Ht, 61.10.Eq, 61.16.Bg

Keywords: metal nanoparticles, ion irradiation, synchrotron radiation 


\section{Introduction}

Metal nanoparticles embedded in a silica matrix have potential technological application in photonic devices and circuits ranging from optical filters to all-optical computers [1]. Intrinsic to many applications is the surface plasmon resonance (SPR) generated by the collective oscillation of conduction electrons in response to external electromagnetic radiation. Characteristic of the SPR is strong optical absorption at a wavelength governed by the nanoparticle composition and shape. For example, spherical Au and Ag nanoparticles absorb at 510 and $400 \mathrm{~nm}$, respectively [2]. For spherical nanoparticles, the absorption maximum depends weakly on nanoparticle diameter [2]. In contrast, rod-like nanoparticles exhibit dual absorption maxima as a result of transverse and longitudinal SPRs. While the former varies only minimally with nanorod width, the latter changes significantly as a function of nanorod length [2]. As a consequence, applicationspecific absorption characteristics can be tuned via the stringent control of the nanoparticle dimensions. For non-spherical shapes, nanoparticle orientation represents an additional variable. For example, the anisotropic alignment of nanorods enables further optimization of absorption maxima as functions of both incident photon polarization and nanorod orientation [3].

For this report, we present recent measurements of the spherical to rod-like shape transformation in embedded elemental metal nanoparticles induced by swift heavy-ion irradiation (SHII). This simple yet effective means of tailoring the size, shape and orientation of metallic nanoparticles can be readily applied to photonic-device-like structures. To our knowledge, this phenomenon was first reported in 2003 by D'Orleans et al [4] who observed the elongation of spherical Co nanoparticles embedded in a silica matrix under $200 \mathrm{MeV}$ I ion irradiation. The nanorods were aligned parallel with the incident ion beam direction which yields advantageous optical characteristics as recently demonstrated for elongated $\mathrm{Ag}$ 
nanoparticles by Oliver et al [3]. Additional experiments with $\mathrm{Au}$ nanoparticles demonstrated the minimum electronic energy deposition required for nanoparticle elongation was comparable to that required to form a molten track in silica [5]. Furthermore, freestanding nanoparticles did not deform thus establishing an intrinsic role for the silica matrix [6]. Though the mechanism governing the change of nanoparticle shape remains unidentified, suggestions as to the means of transformation include: (i) thermal pressure in the nanoparticle inducing creep deformation [4] or simply pressing matter into a molten ion track [7], (ii) stress-driven deformation due to the presence of irradiation-induced strain in the plane perpendicular to the ion beam direction [6], (iii) disintegration in combination with thermodynamic effects, possibly in combination with mechanical effects driven by stress [5] and (iv) thermocapillarity [8]. We now describe new results for the elongation of embedded $\mathrm{Co}, \mathrm{Pt}$ and $\mathrm{Au}$ nanoparticles as a function of the SHII parameters. Our aim is to further the scientific understanding of this technologically-relevant process and better define the shape transformation mechanism.

\section{Experimental}

Elemental metal nanoparticles embedded in amorphous $\mathrm{SiO}_{2}$, the latter thermally grown on Si substrates, were formed by ion implantation and thermal annealing. The range of implantation energies was $0.5-5.0 \mathrm{MeV}$ with the fluence scaled to yield atomic concentrations of approximately 10 at\% or less. A range of annealing temperatures (21$1300^{\circ} \mathrm{C}$ ) and ambients ( $\mathrm{Ar}, \mathrm{O}_{2}$ or forming gas) were used to produce various nanoparticle size distributions with mean diameters spanning 2-15 $\mathrm{nm}$. Complete details of the fabrication protocols are given in references 9, 10 and 11 for Co, Pt and Au nanoparticles, respectively. Nanoparticle samples were then irradiated at room temperature with $27-185 \mathrm{MeV} \mathrm{Au}$ ions as 
a function of fluence. Table I lists the electronic stopping powers calculated with SRIM2006 [12] for $\mathrm{Au}$ ions incident on $\mathrm{SiO}_{2}, \mathrm{Co}, \mathrm{Pt}$ and $\mathrm{Au}$.

Utilising a Philips CM300 microscope operating at $300 \mathrm{kV}$, transmission electron microscopy (TEM) in cross-section geometry was first used to characterise the shape transformation. TEM samples were formed with either conventional ion-beam milling or wafer-cleavage techniques. Complementary determinations of the distribution of nanoparticle dimensions were achieved with small-angle x-ray scattering (SAXS) measurements performed in transmission mode at a wavelength of $1.1 \AA$ (and energy of 11.27 $\mathrm{keV}$ ) using beamline 15ID-D of the Advanced Photon Source, USA. Samples were prepared with a unique methodology described in reference 13. SAXS spectra were analysed with a maximum entropy method as detailed in references 14 and 15. The fraction of Co atoms in metallic and oxidised environments was quantified from x-ray absorption near-edge structure (XANES) experiments performed in fluorescence mode on beamline 20-B of the Photon Factory, Japan. Samples were prepared as described in reference 16. XANES spectra recorded at the Co K-edge were analysed with the IEFFEFIT package [17] using a linear combination of metallic and oxide standards.

\section{Results and Discussion}

Figure 1 shows TEM images of Au nanoparticles subjected to Au ion irradiation at $185 \mathrm{MeV}$. The transformation from spherical to rod-like shape is readily apparent as is the nanorod alignment with the incident ion beam direction. The elongation process is clearly cumulative, requiring fluences of the order $10^{14} \mathrm{~cm}^{-2}$ or equivalently $\sim 250$ overlapping impacts for an ion track of diameter $\sim 11 \mathrm{~nm}$. Figure 2 shows high-resolution TEM images comparing Pt nanoparticles before and after irradiation $\left(185 \mathrm{MeV} / 2 \times 10^{14} \mathrm{~cm}^{-2}\right)$. While the as-formed nanoparticles are typically single crystalline, subsequent to irradiation their 
polycrystalline nature is evident. The latter may well be indicative of nanoparticle melting during the elongation process.

Figure 3 shows TEM measurements of the Pt nanorod width $\left(\mathrm{D}_{\text {minor }}\right)$ as a function of nanorod length $\left(\mathrm{D}_{\text {major }}\right)$ subsequent to $185 \mathrm{MeV}$ Au ion irradiation. Clearly nanoparticles of diameter $<\sim 6 \mathrm{~nm}$ remain spherical upon irradiation. Given the surface-area-to-volume ratio increases as nanoparticle size decreases, nanoparticles below this threshold may retain a spherical shape to minimise the interfacial contribution to total energy. Nanoparticles above the threshold are progressively transformed as a function of irradiation fluence. For this irradiation energy (185 MeV), the nanorod width eventually saturates at $\sim 6 \mathrm{~nm}$ while the distribution of nanorod lengths is broad, consistent with a similarly broad distribution of spherical nanoparticle diameters prior to irradiation. The threshold diameter for elongation of spherical nanoparticles is evidently comparable to the saturation width of transformed nanorods. Figure 4 is a further TEM image of irradiated Pt nanoparticles (185 MeV/6x $10^{14}$ $\mathrm{cm}^{-2}$ ) and readily demonstrates a threshold diameter for the shape transformation - elongated nanorods with aspect ratios exceeding 10 are readily apparent yet interspersed with spherical nanoparticles of diameters $<\sim 6 \mathrm{~nm}$. We have yet to observe a maximum nanoparticle diameter above which elongation does not occur. However, with increasing size the nanoparticle properties become more and more bulk-like and, as a consequence, very large metallic nanoparticles should exhibit greater insensitivity to SHII. Calculations for Co nanoparticles show those of diameter $<20 \mathrm{~nm}$ melt upon $200-\mathrm{MeV}$ I ion irradiation while those of greater size remain in the solid phase [4]. None-the-less, we have observed elongation of $\sim 50-\mathrm{nm}$ diameter Co nanoparticles under Au ion irradiation at $185 \mathrm{MeV}$.

SAXS and TEM measurements of the distribution of Co nanorod dimensions are compared in Figure 5. As above, the as-formed spherical nanoparticles have a broad distribution, centered at approximately $12 \mathrm{~nm}$. The irradiation conditions $\left(185 \mathrm{MeV} / 6 \times 10^{14}\right.$ 
$\mathrm{cm}^{-2}$ ) were sufficient to saturate the nanorod width. Clearly the distribution for $\mathrm{D}_{\text {minor }}$ has narrowed relative to the as-formed spheres and demonstrates the capabilities of SHII for the production of aligned nanorods of a specific width. In contrast, the distribution of $\mathrm{D}_{\text {major }}$ is broad. The greatest aspect ratios are typically observed at intermediate fluences beyond which nanoparticles are both dissolved and fragmented. Figure 6 shows XANES measurements of the fraction of $\mathrm{Co}$ atoms in metallic and oxidised environments as a function of $\mathrm{Au}$ ion fluence and energy. The progressive dissolution of Co nanoparticles/nanorods into the matrix (or, equivalently, into an oxidised environment) is evident. The process is clearly non-ballistic, increasing in rate for the higher irradiation energies. Small nanoparticles dissolved more rapidly than their larger counterparts (not shown), consistent with a greater surface-area-to-volume ratio. Evidence of nanorod fragmentation is highlighted with arrows in Figure 4 and bears the characteristics of a Rayleigh instability mechanism. The volume of elongated nanoparticles is not conserved upon irradiation in contrast to previous reports [4].

Figure 7 shows TEM measurements of the saturated width of Pt nanorods over the entire range of irradiation energies, where the fluence was increased until saturation was achieved. Clearly the saturation value of the nanorod width increases with increasing irradiation energy or, equivalently, with electronic energy deposition. Figure 8 summarises our findings for the saturation width of metallic nanorods as a function of electronic energy deposition. For comparison, experimental determinations of the molten ion track diameter in silica [18] are also included. The three metals examined in this study exhibit similar behavior and, intriguingly, their saturation width is well correlated with the diameter of the once molten track. Accordingly, we suggest the former is governed to a large extent by the latter. In terms of a transformation mechanism, our results are consistent with the elongation of a once-spherical molten nanoparticle confined to the diameter of the molten ion track in silica. 


\section{Conclusions}

We have combined laboratory- and synchrotron-based techniques to characterise changes in the shape and size of elemental metallic nanoparticles induced by swift heavy-ion irradiation. A threshold diameter for nanoparticle elongation has been established, below which nanoparticles remain spherical under irradiation and are progressively dissolved in the matrix. Spherical nanoparticles above the threshold are transformed to elongated and oriented rods. The nanorod width saturates at a value that increases with electronic energy deposition and is comparable to the threshold diameter for spherical nanoparticle elongation. This saturation value of nanorod width is less than the diameter of the molten track induced in amorphous $\mathrm{SiO}_{2}$ by swift heavy-ion irradiation. For the given size distributions, the elongation of $\mathrm{Co}, \mathrm{Pt}$ and $\mathrm{Au}$ nanoparticles was, in general, similar and is thus primarily governed by the irradiation parameters. Subtle material-specific differences are now under investigation.

\section{Acknowledgements}

We thank the Australian Research Council and Australian Synchrotron Research Program for financial support.

\section{References}

[1] T.-H. Lee and R.M. Dickson, Optics and Photonics News (June 2004) 22.

[2] S. Link and M.A. El-Sayed, J.Phys.Chem. B 103 (1999) 8410.

[3] A. Oliver, J.A. Reyes-Esqueda, J.C. Cheang-Wong, C.E. Roman-Velazquez, A. Crespo-Sosa, L. Rodriguez-Fernandez, J.A. Seman and C. Noguez, Phys.Rev. B $\underline{74}$ (2006) 245425. 
[4] C. D’Orleans, J.P. Stoquert, C. Estournes, C. Cerruti, J.J. Grob, J.L. Guille, F. Haas, D. Muller and M. Richard-Plouet, Phys.Rev. B $\underline{67}$ (2003) 220101.

[5] J.J. Penninkhof, T. van Dillen, S. Roorda, C. Graf, A. van Blaaderen, A.M. Vredenberg and A. Polman, Nucl.Instrum.Meth. B 242 (2006) 523.

[6] S. Roorda, T. van Dillen, A. Polman, C. Graf, A. van Blaaderen and B.J. Kooi, Adv.Mat. $\underline{16}$ (2004) 235.

[7] S. Klaumunzer, Nucl.Instrum.Meth. B 244 (2006) 1.

[8] K.-H. Heinig, A. Vredenberg, M. Toulemonde and K. Nordlund, abstract A-267 presented at the $15^{\text {th }}$ International Conference on Ion Beam Modification of Materials, Italy, 2008.

[9] Co nanoparticles were prepared by multiple energy Co ion implantations of 500-1400 $\mathrm{keV}$ into amorphous $\mathrm{SiO}_{2}$ with fluences of $3.8 \times 10^{15}-3.0 \times 10^{17} \mathrm{~cm}^{-2}$ yielding $\mathrm{Co}$ concentrations of $0.3-9.0$ at.\%. Samples were then annealed at 500,800 or $1100^{\circ} \mathrm{C}$ for $1 \mathrm{~h}$ in $5 \% \mathrm{H}_{2} / 95 \% \mathrm{~N}_{2}$ to promote nanoparticle nucleation and growth.

[10] R. Giulian, P. Kluth, L.L. Araujo, D.J. Llewellyn and M.C. Ridgway, Appl.Phys.Lett. $\underline{91}$ (2007) 93115.

[11] P. Kluth, B. Johannessen, V. Giraud, A. Cheung, C.J. Glover, G. de M. Azevedo, G.J. Foran and M.C. Ridgway, Appl.Phys.Lett. $\underline{85}$ (2004) 3561.

[12] J.F. Ziegler, J.P. Biersack and U. Littmark, The Stopping and Range of Ions in Solids (Pergamon Press, New York) 1985.

[13] R. Giulian, P. Kluth, B. Johannessen, L.L. Araujo, D.J. Llewellyn, G.J. Foran, D.J. Cookson and M.C. Ridgway, Nucl.Instrum.Meth. B257 (2007) 33.

[14] R. Giulian P. Kluth, L.L. Araujo, D.J. Sprouster, A.P. Byrne, D.J. Cookson and M.C. Ridgway, Phys.Rev. (2008) in press. 
[15] P. Kluth, B. Johannessen, G.J. Foran, D.J. Cookson, S.M. Kluth and M.C. Ridgway, Phys.Rev. B74 (2006) 014202.

[16] B. Johannessen, P. Kluth, D.J. Llewellyn, G.J. Foran, D.J. Cookson and M.C. Ridgway, Phys.Rev. B $7 \underline{6}$ (2007) 184203.

[17] M. Newville, J.Sync.Rad. $\underline{8}$ (2001) 322.

[18] The molten ion track diameter was determined from transmission SAXS measurements of amorphous $\mathrm{SiO}_{2}$ layers (without nanoparticles) on $\mathrm{Si}$ substrates following very low fluence (to avoid track overlap) Au ion irradiations using the same ion energies as listed herein. Full details will be published by P. Kluth et al. 


\section{Figure Captions}

Figure One: Cross-sectional TEM images of Au nanoparticles in $\mathrm{SiO}_{2}$ irradiated with 185 $\mathrm{MeV} \mathrm{Au} \mathrm{ions} \mathrm{as} \mathrm{a} \mathrm{function} \mathrm{of} \mathrm{fluence}\left(\mathrm{cm}^{-2}\right)$. The Au ion beam was oriented in the vertical direction.

Figure Two: High-resolution TEM images of Pt nanoparticles before and after irradiation $\left(185 \mathrm{MeV} / 2 \times 10^{14} \mathrm{~cm}^{-2}\right)$.

Figure Three: TEM measurements of nanorod width as a function of nanorod length for Pt nanoparticles irradiated with $185 \mathrm{MeV} \mathrm{Au}$ ions as a function of fluence.

Figure Four: Cross-sectional TEM image of irradiated Pt nanoparticles (185 MeV/6x10 14 $\left.\mathrm{cm}^{-2}\right)$.

Figure Five: TEM and SAXS measurements of the distributions of spherical Co nanoparticle diameter before irradiation and nanorod width $\left(D_{\text {minor }}\right)$ and length $\left(D_{\text {major }}\right)$ after irradiation (185 MeV/6x10 $\left.10^{14} \mathrm{~cm}^{-2}\right)$.

Figure Six: $\quad$ XANES measurements of the fraction of Co atoms in metallic and oxidised environments for Co nanoparticles of diameter $12 \mathrm{~nm}$ irradiated with $\mathrm{Au}$ ions as a function of fluence and energy. 
Figure Seven: TEM measurements of saturated nanorod width $\left(\mathrm{D}_{\text {minor }}\right)$ as a function of nanorod length $\left(\mathrm{D}_{\text {major }}\right)$ for $\mathrm{Pt}$ nanoparticles with different $\mathrm{Au}$ ion energy/fluence combinations.

Figure Eight: Saturated nanorod width for $\mathrm{Co}, \mathrm{Pt}$ and Au nanoparticles and molten ion track diameter as a function of electronic stopping power ( $\mathrm{Au}$ ions in $\mathrm{SiO}_{2}$ ). 
Table Captions

Table I: $\quad$ Electronic stopping powers $(\mathrm{keV} / \mathrm{nm})$ for $\mathrm{Au}$ ion irradiation as a function of target material and ion energy. 
Table I

\begin{tabular}{|l|l|l|l|l|}
\hline & $\mathbf{2 7} \mathbf{~ M e V}$ & $\mathbf{5 5} \mathbf{~ M e V}$ & $\mathbf{8 9} \mathbf{~ M e V}$ & $\mathbf{1 8 5} \mathbf{~ M e V}$ \\
\hline $\mathbf{S i O}_{\mathbf{2}}$ & 4.7 & 9.0 & 12.6 & 17.6 \\
\hline $\mathbf{C o}$ & 9.4 & 19.8 & 29.8 & 45.1 \\
\hline $\mathbf{P t}$ & 10.3 & 22.0 & 33.9 & 54.9 \\
\hline $\mathbf{A u}$ & 9.3 & 19.8 & 30.8 & 50.0 \\
\hline
\end{tabular}


Figure 1

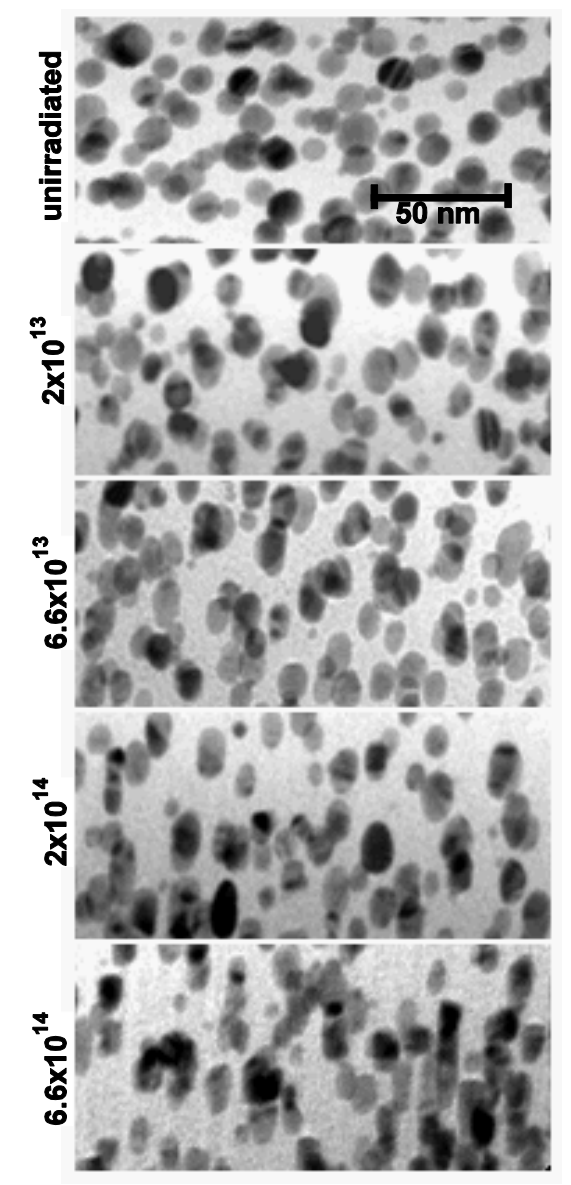


Figure 2

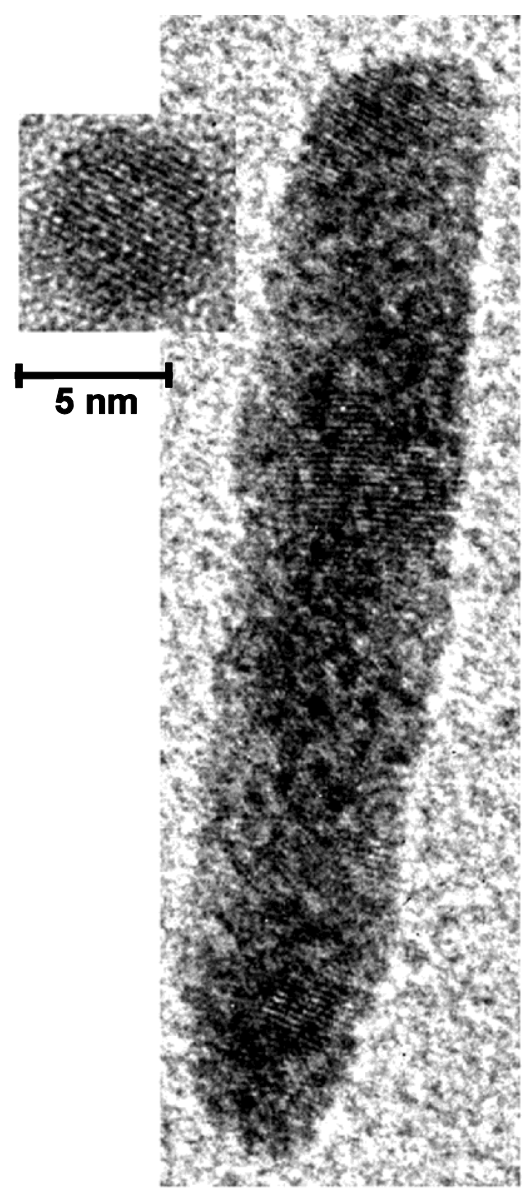


Figure 3

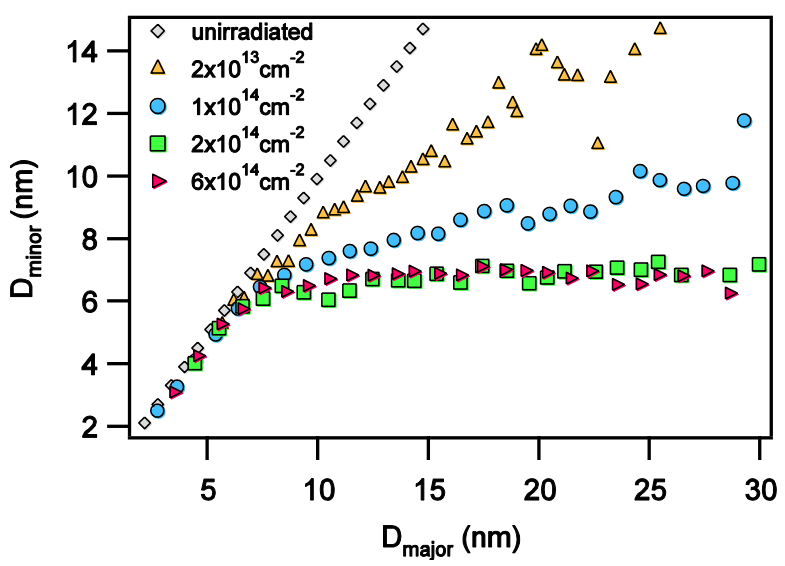


Figure 4

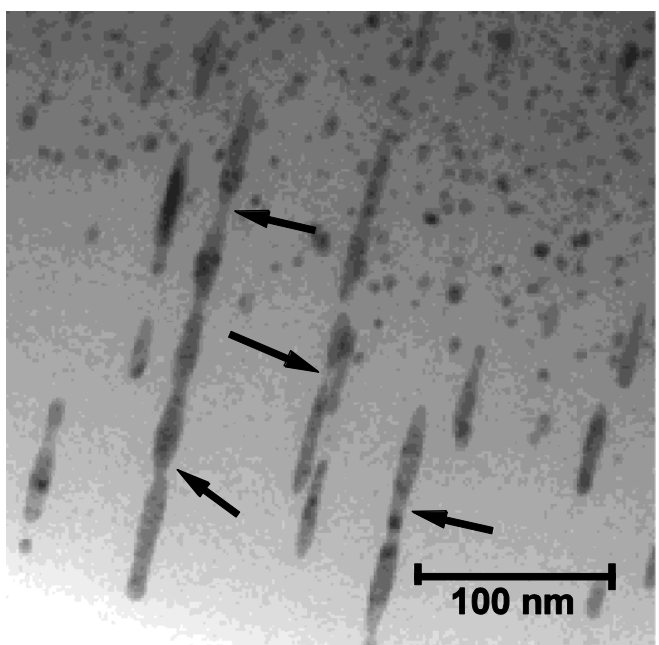


Figure 5

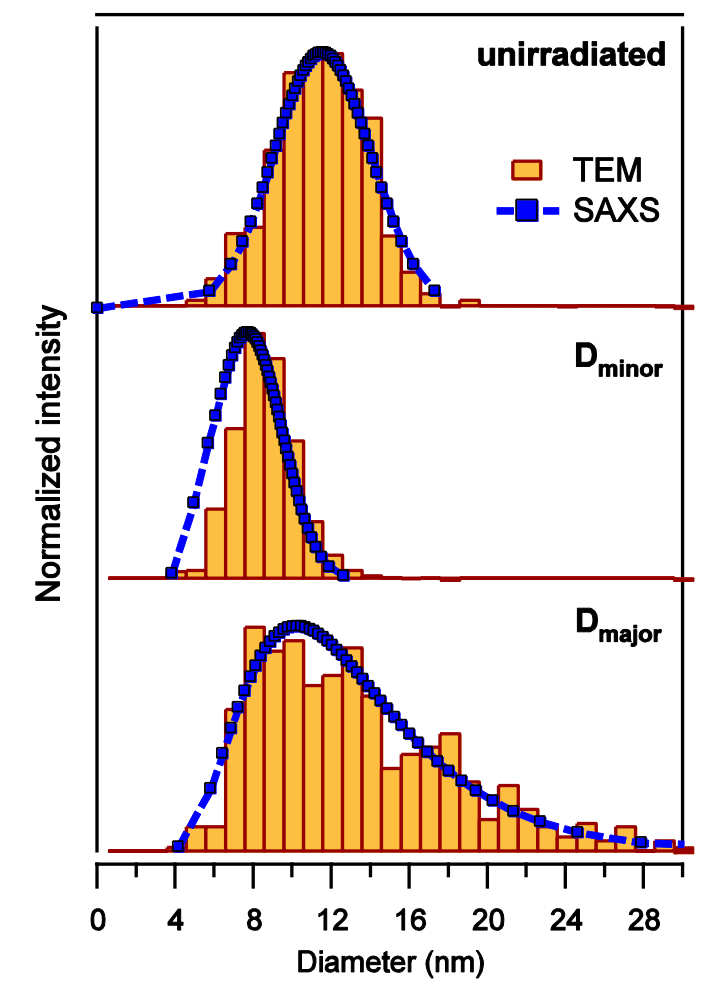


Figure 6

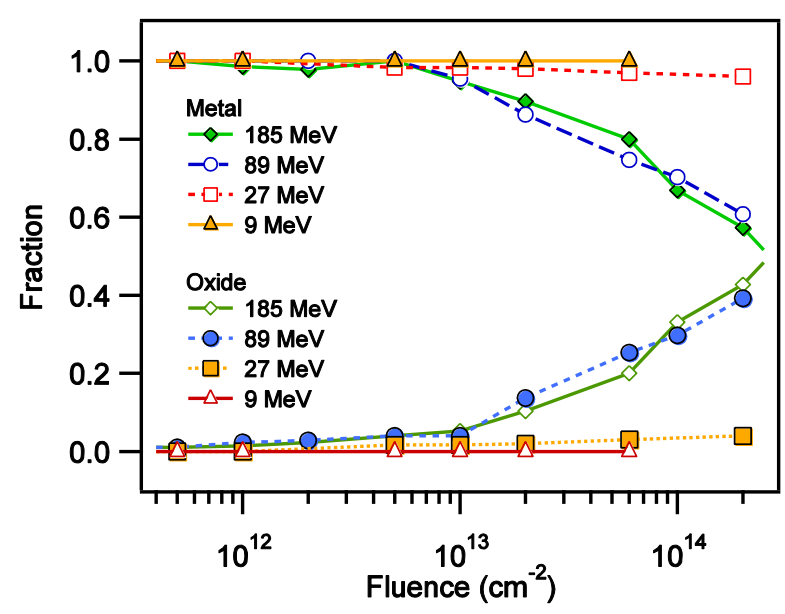


Figure 7

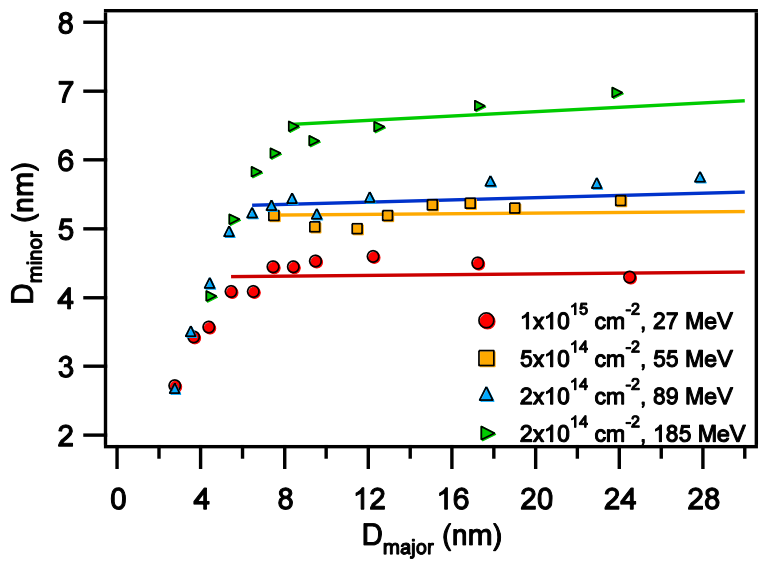


Figure 8

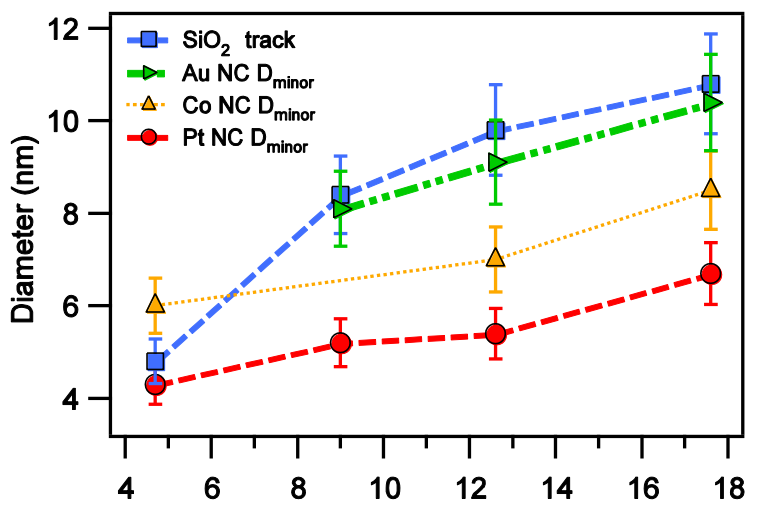

Electronic Stopping Power (keV/nm) 